\title{
Effect of nanoparticle size on nucleate pool boiling heat transfer of refrigerant/oil mixture with nanoparticles
}

\author{
Hao Peng ${ }^{\mathrm{a}, \mathrm{b}}$, Guoliang Ding ${ }^{\mathrm{a}, *}$, Haitao $\mathrm{Hu}^{\mathrm{a}}$, Weiting Jiang ${ }^{\mathrm{a}}$ \\ a Institute of Refrigeration and Cryogenics, Shanghai Jiaotong University, 800 Dongchuan Road, Shanghai 200240, China \\ ${ }^{\mathrm{b}}$ Key Laboratory of Microgravity (National Microgravity Laboratory) / CAS; Institute of Mechanics, Chinese Academy of Sciences (CAS), 15 Beisihuan Xilu, Beijing 100190, China
}

\section{A R T I C L E I N F O}

Article history:

Received 12 January 2010

Received in revised form 15 November 2010

Accepted 10 December 2010

\section{Keywords:}

Nanoparticle size

Nucleate boiling

Refrigerant

Oil

Correlation

\begin{abstract}
A B S T R A C T
Effect of nanoparticle size on nucleate pool boiling heat transfer of refrigerant/oil mixture with nanoparticles was investigated experimentally. For the preparation of the test fluid, refrigerant R113, ester oil VG68, and Cu nanoparticles with three different average diameters of 20, 50 and $80 \mathrm{~nm}$ were used. Experimental conditions include a saturation pressure of $101.3 \mathrm{kPa}$, heat fluxes from 10 to $80 \mathrm{~kW} \mathrm{~m}^{-2}$, nanoparticle concentrations in the nanoparticles/oil suspension from 0 to $30 \mathrm{wt} \%$, and nanoparticles/oil suspension concentrations from 0 to $5 \mathrm{wt} \%$. The experimental results indicate that the nucleate pool boiling heat transfer coefficient of R113/oil mixture with $\mathrm{Cu}$ nanoparticles is enhanced by a maximum of $23.8 \%$ with the decrease of nanoparticle size from 80 to $20 \mathrm{~nm}$ under the present experimental conditions, and the enhancement increases with the decrease of nanoparticles/oil suspension concentration or the increase of nanoparticles concentrations in the nanoparticles/oil suspension. A general nucleate pool boiling heat transfer coefficient correlation for refrigerant/oil mixture with nanoparticles is proposed, and it agrees with $93 \%$ of the existing experimental data of refrigerant/oil mixture with nanoparticles within a deviation of $\pm 20 \%$.
\end{abstract}

() 2011 Elsevier Ltd. All rights reserved.

\section{Introduction}

As a new type heat transfer fluid, nanofluid (i.e., the mixture of host fluid and nanoparticles) can be used to enhance the heat transfer of heat exchangers. The nanoparticle size has significant effects on the thermophysical properties of nanofluid [1-3] and the convective heat transfer characteristics of nanofluid [4-6], so it may have effects on the overall performance of the heat exchangers using nanofluid. In recent years, nanofluids have been used for improving the performance of vapor compression refrigeration systems [7-9]. In the air-cooled evaporators, the boiling heat transfer in evaporators is the flow boiling heat transfer inside tubes. In the flooded evaporators, the boiling heat transfer in evaporators is the pool boiling outside tube surfaces. For most refrigeration systems, the air-cooled evaporators are used, and lubricating oil used in the compressor circulates with the working refrigerant. In order to evaluate the effect of nanoparticle size on the overall performance of air-cooled evaporators in refrigeration systems, the effect of nanoparticle size on the flow boiling heat transfer of refrigerant/ oil mixture with nanoparticles inside tubes should be known. As the flow boiling heat transfer is the combination of nucleate pool boiling heat transfer and convective heat transfer, the effect of

\footnotetext{
* Corresponding author. Tel.: +86 21 34206378, fax: +86 2134206814 .

E-mail address: glding@sjtu.edu.cn (G. Ding).
}

nanoparticle size on the nucleate pool boiling heat transfer of refrigerant/oil mixture with nanoparticles on horizontal surface needs to be investigated firstly in order to know how nanoparticle size influences boiling heat transfer inside an evaporator.

The research on the nucleate pool boiling heat transfer characteristics of refrigerant/oil mixture with nanoparticles or pure refrigerant with nanoparticles have been reported in literatures [10-12]. Experiments on the nucleate pool boiling heat transfer of R134a/oil mixture with $\mathrm{CuO}$ nanoparticles showed that the $\mathrm{CuO}$ nanoparticles cause a heat transfer enhancement compared with the heat transfer of R134a/oil mixture [10]. Experiments on the nucleate pool boiling heat transfer of R113/oil mixture with diamond nanoparticles showed that the diamond nanoparticles also cause a heat transfer enhancement compared with the heat transfer of R113/oil mixture, and the enhancement effect of diamond nanoparticle on the nucleate pool boiling heat transfer is higher than that of $\mathrm{CuO}$ nanoparticle at the same condition [11]. Experiment on the nucleate pool boiling heat transfer of pure $\mathrm{R} 141 \mathrm{~b}$ with $\mathrm{TiO}_{2}$ nanoparticles showed that the nucleate pool boiling heat transfer deteriorates with the increase of nanoparticle concentration, especially at high heat fluxes [12]. However, nanoparticles of only one size were used in each of the above research, and the effect of nanoparticle size on the nucleate pool boiling heat transfer of refrigerant/oil mixture with nanoparticles or pure refrigerant with nanoparticles was not investigated. 


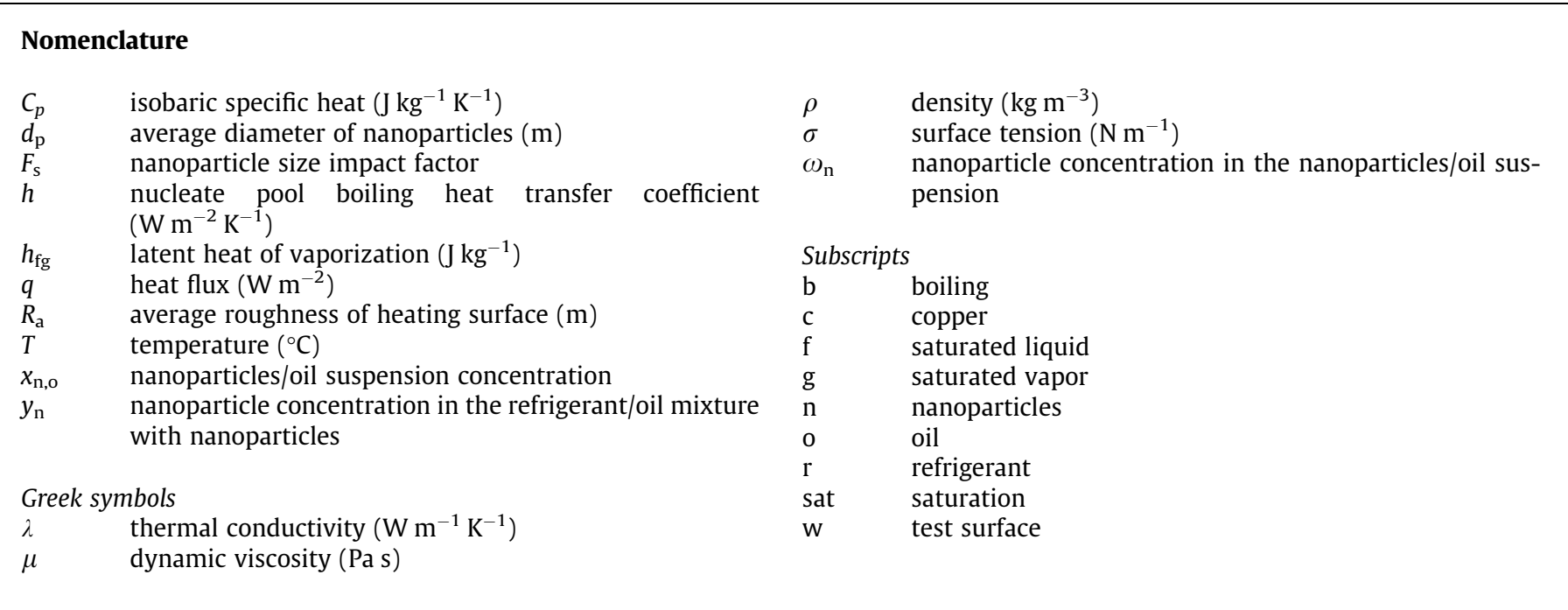

For the effect of nanoparticle size on the nucleate pool boiling heat transfer characteristics of nanofluids, the research are focused on the water-based nanofluids $[13,14]$. Experiments on the nucleate pool boiling of water-based nanofluids with alumina nanoparticles (average sizes of 47 and $150 \mathrm{~nm}$ ) on vertical tubular heaters with various surface roughnesses $(48,98$ and $524 \mathrm{~nm}$ ) showed that the heat transfer is decreased when the average particle size is of the order of the surface roughness, and is greatly increased when the average particle size is much smaller than the surface roughness [13]. Experiments on the nucleate pool boiling of water-based nanofluids containing alumina nanoparticles (average sizes of 47 and $150 \mathrm{~nm}$ ) on a smooth tube (average surface roughness of $48 \mathrm{~nm}$ ) showed that the lesser number of larger particles $(150 \mathrm{~nm})$ are in the range of the average surface roughness, and the nanofluid with larger particles $(150 \mathrm{~nm})$ provides higher heat transfer [14]. As the thermophysical properties of refrigerant/oil mixture are different from those of water, the effect of nanoparticle size on the nucleate pool boiling heat transfer characteristics of refrigerant/oil mixture with nanoparticles may be different from that of water-based nanofluid. Therefore, it is necessary to investigate the effect of nanoparticle size on the nucleate pool boiling heat transfer characteristics of refrigerant/oil mixture with nanoparticles.

For predicting the nucleate pool boiling heat transfer coefficient of refrigerant/oil mixture with nanoparticles, Peng et al. [11] proposed a correlation, in which the effects of nanoparticle types (CuO and diamond) and host fluid types (R134a/RL68H mixture and R113/VG68 mixture) are reflected. However, the effect of nanoparticle size is not considered in this correlation.

The purpose of this study emphasizes on the effect of nanoparticle size on the nucleate pool boiling heat transfer characteristics of refrigerant/oil mixture with nanoparticles. Different from the study by Peng et al. [11], the nanoparticles with different sizes are used in the present experimental study instead of the nanoparticles of only one size used in the study by Peng et al. [11]. Moreover, a novel correlation is proposed by introducing the size effect to improve the published Peng's correlation which does not consider the effect of nanoparticle size.

\section{Preparation and characterization of refrigerant/oil mixture with nanoparticles}

In order to investigate the effect of nanoparticle size on the nucleate pool boiling heat transfer characteristics of refrigerant/ oil mixture with nanoparticles, three types of $\mathrm{Cu}$ nanoparticles pro- duced by hydrogen direct current arc plasma evaporation method are used. The median nanoparticle diameters of these three types of $\mathrm{Cu}$ nanoparticles are in the ranges of $10-30 \mathrm{~nm}, 30-60 \mathrm{~nm}$, and $60-100 \mathrm{~nm}$, respectively. Their average diameters $\left(d_{\mathrm{p}}\right)$ are $20 \mathrm{~nm}, 50 \mathrm{~nm}$ and $80 \mathrm{~nm}$, as reported by the manufacturer. The properties of $\mathrm{Cu}$ nanoparticles are given in Table 1, and the TEM (transmission electron microscope) photographs of $\mathrm{Cu}$ nanoparticles are shown in Fig. 1.

R113 is in liquid state at ambient temperature and pressure while the widely used refrigerants (e.g., R410A and R134a) are in vapor state, so it is much easier to prepare well-dispersed refrigerant/oil mixture with nanoparticles based on R113 than that based on the widely used refrigerants (e.g., R410A and R134a). Therefore, R113 is chosen as the host refrigerant in the present study, just as Ding et al. [15] and Peng et al. [11] did. The properties of refrigerant R113 are given in Table 2.

For the preparation of refrigerant/oil mixture with nanoparticles, the lubricating oil VG68 is used. VG68 is an ester oil with a density of $0.964 \mathrm{~g} \mathrm{~cm}^{-3}$ at $15^{\circ} \mathrm{C}$ and kinematic viscosities of 66.79 and $8.23 \mathrm{~mm}^{2} \mathrm{~s}^{-1}$ at $40^{\circ} \mathrm{C}$ and $100{ }^{\circ} \mathrm{C}$, respectively, as reported by the manufacturer. No surfactant is used in the present study in order to avoid the sorption and agglutination phenomenon during nanofluid boiling heat transfer process [16] and the disturbance of surfactant on the pool boiling heat transfer characteristics of the nanofluid $[12,17,18]$.

R113/oil mixture with $\mathrm{Cu}$ nanoparticles is prepared by the following steps: (1) weighing the required mass of $\mathrm{Cu}$ nanoparticles by a digital electronic balance with a measurement range of $10 \mathrm{mg}$ to $210 \mathrm{~g}$ and a maximum error of $0.1 \mathrm{mg}$; (2) putting the $\mathrm{Cu}$ nanoparticles into the weighed lubricating oil VG68 to form a $\mathrm{Cu}$ nanoparticles/oil suspension; (3) putting the $\mathrm{Cu}$ nanoparticles/oil suspension into the weighed R113 to form a R113/oil mixture with Cu nanoparticles; (4) vibrating the R113/oil mixture with $\mathrm{Cu}$ nanoparticles by an ultrasonic processor for $1 \mathrm{~h}$ to stabilize the dispersion of nanoparticles. Experimental observation shows that

Table 1

Properties of $\mathrm{Cu}$ nanoparticles.

\begin{tabular}{lll}
\hline Property & Unit & Value \\
\hline Atomic mass & $\mathrm{g} / \mathrm{mol}$ & 63.54 \\
Average particle diameter & $\mathrm{nm}$ & $20,50,80$ \\
Density & $\mathrm{kg} \mathrm{m}^{-3}$ & 8920 \\
Thermal conductivity & $\mathrm{W} \mathrm{m}^{-1} \mathrm{~K}^{-1}$ & 398 \\
Isobaric specific heat & $\mathrm{J} \mathrm{kg}^{-1} \mathrm{~K}^{-1}$ & 385 \\
\hline
\end{tabular}




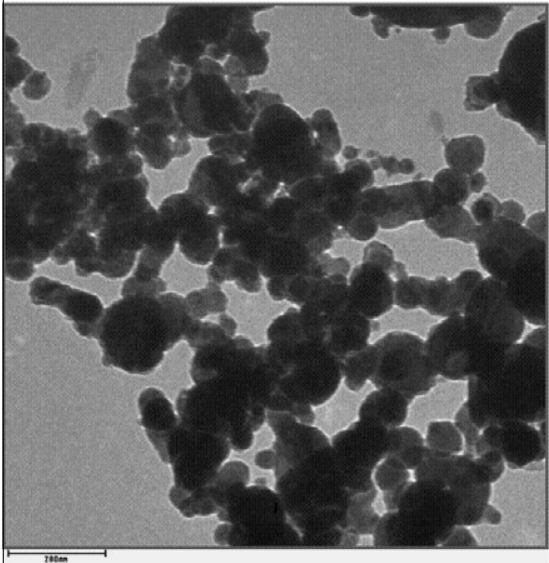

(a) $20 \mathrm{~nm}$

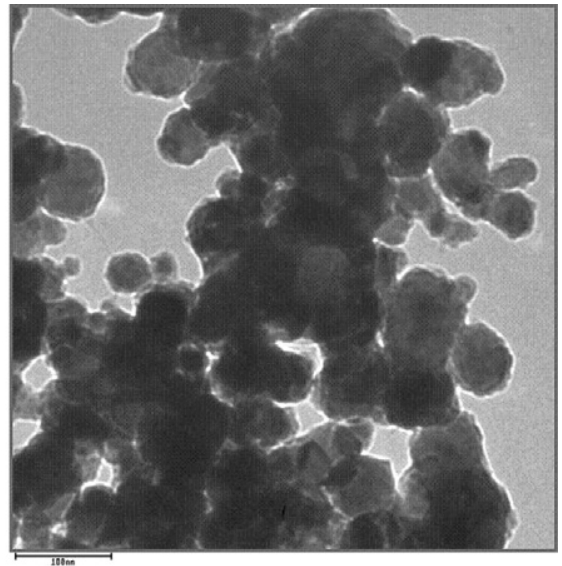

(b) $50 \mathrm{~nm}$

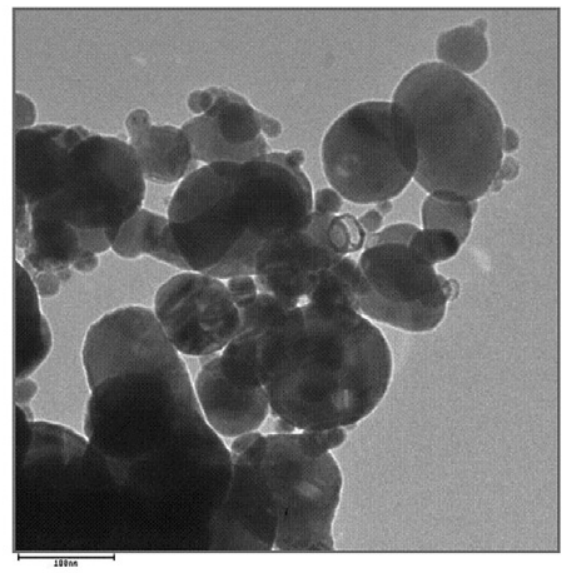

(c) $80 \mathrm{~nm}$

Fig. 1. TEM photographs of Cu nanoparticles: (a) $20 \mathrm{~nm}$; (b) $50 \mathrm{~nm}$ and (c) $80 \mathrm{~nm}$.

Table 2

Properties of refrigerant R113.

\begin{tabular}{llc}
\hline Property & Unit & Value or format \\
\hline Chemical formula & - & Cl2FC-CClF2 \\
Molecular mass & $\mathrm{g} / \mathrm{mol}$ & 187.37 \\
Normal boiling point & ${ }^{\circ} \mathrm{C}$ & 47.6 \\
Critical temperature & ${ }^{\circ} \mathrm{C}$ & 214.1 \\
Critical pressure & $\mathrm{MPa}$ & 3.39 \\
\hline
\end{tabular}

the stable dispersion of Cu nanoparticles can be kept for more than $12 \mathrm{~h}$ without coagulation or deposition. The duration of the experiment for each sample of R113/oil mixture with $\mathrm{Cu}$ nanoparticles is less than $4 \mathrm{~h}$ which is much shorter than $12 \mathrm{~h}$, so the R113/oil mixture with $\mathrm{Cu}$ nanoparticles can maintain good uniformity in the experiment.

In order to conveniently describe the composition of the R113/ oil mixture with $\mathrm{Cu}$ nanoparticles, the following concentrations are defined in this paper.

(1) Nanoparticle concentration in the nanoparticles/oil suspension, $\omega_{n}$, is defined as the ratio of the mass of nanopaticles to the mass of nanoparticles/oil suspension, shown as Eq. (1):

$$
\omega_{\mathrm{n}}=\frac{m_{\mathrm{n}}}{m_{\mathrm{n}}+m_{\mathrm{o}}}
$$

where $m_{\mathrm{n}}$ is the mass of nanoparticles, and $m_{\mathrm{o}}$ is the mass of lubricating oil.

(2) Nanoparticles/oil suspension concentration, $x_{n, 0}$, is defined as the ratio of the mass of nanoparticles/oil suspension to the mass of refrigerant/oil mixture with nanoparticles, shown as Eq. (2):

$x_{\mathrm{n}, \mathrm{o}}=\frac{m_{\mathrm{n}, \mathrm{o}}}{m_{\mathrm{n}, \mathrm{o}}+m_{\mathrm{r}}}$

where $m_{n, o}$ is the mass of nanoparticles/oil suspension, and $m_{\mathrm{r}}$ is the mass of refrigerant.

(3) Nanoparticle concentration in the refrigerant/oil mixture with nanoparticles, $y_{\mathrm{n}}$, is defined as the ratio of the mass of nanoparticles to the mass of refrigerant/oil mixture with nanoparticles, and is calculated by Eq. (3):

$$
y_{\mathrm{n}}=\omega_{\mathrm{n}} \cdot x_{\mathrm{n}, \mathrm{o}}
$$

In the present study, three R113/oil mixtures with Cu nanoparticles, containing nanoparticles/oil suspension at concentrations $\left(x_{\mathrm{n}, \mathrm{o}}\right)$ of 1 , 3 and $5 \mathrm{wt} \%$, respectively, are prepared. For $x_{\mathrm{n}, \mathrm{o}}=1 \mathrm{wt} \%$, the nanoparticle concentrations in the nanoparticles/oil suspension $\left(\omega_{n}\right)$ are 10,20 and $30 \mathrm{wt} \%$. For $x_{\mathrm{n}, \mathrm{o}}=3 \mathrm{wt} \%$ and $x_{\mathrm{n}, \mathrm{o}}=5 \mathrm{wt} \%$, the value of $\omega_{\mathrm{n}}$ is $20 \mathrm{wt} \%$. Correspondingly, there are five nanoparticle concentrations in the refrigerant/oil mixture with nanoparticles $\left(y_{n}\right)$, i.e., $0.1,0.2,0.3,0.6$ and $1.0 \mathrm{wt} \%$, as shown in Table 3. 
Table 3

Test conditions.

\begin{tabular}{|c|c|c|c|c|c|}
\hline Test fluid and its composition (mass fraction in the mixture) & $\omega_{n}(\mathrm{wt} \%)$ & $x_{n, \mathrm{o}}(\mathrm{wt} \%)$ & $y_{n}(\mathrm{wt} \%)$ & Heat flux $\left(\mathrm{kW} \mathrm{m}^{-2}\right)$ & Saturation pressure $(\mathrm{kPa})$ \\
\hline R113/VG68 (99/1) & - & - & - & $10-80$ & 101.3 \\
\hline R113/VG68 (97/3) & - & - & - & & \\
\hline R113/VG68 (95/5) & - & - & - & & \\
\hline R113/VG68/20nm-Cu (99/0.8/0.2) & 20 & 1 & 0.2 & & \\
\hline R113/VG68/50nm-Cu (99/0.8/0.2) & 20 & 1 & 0.2 & & \\
\hline R113/VG68/80nm-Cu (99/0.8/0.2) & 20 & 1 & 0.2 & & \\
\hline R113/VG68/20nm-Cu (97/2.4/0.6) & 20 & 3 & 0.6 & & \\
\hline R113/VG68/50nm-Cu (97/2.4/0.6) & 20 & 3 & 0.6 & & \\
\hline R113/VG68/80nm-Cu (97/2.4/0.6) & 20 & 3 & 0.6 & & \\
\hline R113/VG68/20nm-Cu (95/4/1) & 20 & 5 & 1 & & \\
\hline R113/VG68/50nm-Cu (95/4/1) & 20 & 5 & 1 & & \\
\hline R113/VG68/80nm-Cu (95/4/1) & 20 & 5 & 1 & & \\
\hline R113/VG68/20nm-Cu (99/0.9/0.1) & 10 & 1 & 0.1 & & \\
\hline R113/VG68/50nm-Cu (99/0.9/0.1) & 10 & 1 & 0.1 & & \\
\hline R113/VG68/80nm-Cu (99/0.9/0.1) & 10 & 1 & 0.1 & & \\
\hline R113/VG68/20nm-Cu (99/0.7/0.3) & 30 & 1 & 0.3 & & \\
\hline R113/VG68/50nm-Cu (99/0.7/0.3) & 30 & 1 & 0.3 & & \\
\hline R113/VG68/80nm-Cu (99/0.7/0.3) & 30 & 1 & 0.3 & & \\
\hline
\end{tabular}

\section{Experimental facility and procedure}

\subsection{Experimental facility}

Similar to that used by Peng et al. [11], the experimental facility used for testing the nucleate pool boiling heat transfer characteristics of the refrigerant/oil mixture with nanoparticles consists of three parts (i.e., a test section, a boiling apparatus and a condensation loop), as schematically shown in Fig. 2.

(1) The test section is fabricated by a copper block. Fig. 3 shows the geometry and size of the test section. Generally, several thermocouples are needed in the test section to obtain the temperature gradient of the test surface accurately, and then to calculate the heat flux and the test surface temperature [18]. In the present study, five calibrated K-type thermocouples with the precision of $\pm 0.1^{\circ} \mathrm{C}$ are inserted into five $1.0 \mathrm{~mm}$ diameter holes in the top part of the copper block. A cartridge heater is inserted into the copper block from the bottom, and it provides the copper block with the needed heating power. A voltage regulator and a power meter are connected with the cartridge heater to adjust and display the heating power, respectively. The top surface of the copper block is horizontal, and is used as the test surface for pool boiling heat transfer experiments. This surface is circular with a diameter of $20.0 \mathrm{~mm}$, and flat with an average roughness $\left(R_{\mathrm{a}}\right)$ of $1.6 \mu \mathrm{m}$.

(2) The boiling apparatus mainly consists of a transparent glass chamber, an electrical heating wire and a charge device for refrigerant/oil mixture with nanoparticles. The transparent glass chamber with the size of $150.0 \mathrm{~mm} \times 150.0 \mathrm{~mm}$ $\times 200.0 \mathrm{~mm}$ is used to contain the test fluid. The bottom of the boiling chamber is a copper plate with a circular hole at the center. The copper block is linked with the copper plate by a Teflon connector, ensuring the test surface exposed in the pool liquid. One part of the copper block is under the plate, and insulated with glass fibers to reduce heat loss to the surroundings. The top of the boiling chamber is also a copper plate with seven circular holes, which are connected with the inlet and outlet of the condensation loop, the inlet and outlet of electrical heating wire, the charge device for refrigerant/ oil mixture with nanoparticles, the vacuum pump and the Ktype thermocouple for measuring the liquid temperature. The electrical heating wire is an auxiliary heater to maintain the nucleate boiling of the test fluid and to control the saturation pressure. A pressure transducer with the precision of $\pm 0.1 \mathrm{kPa}$ connected with the transparent glass chamber is used to monitor the pressure inside the chamber.

(3) The condensation loop mainly consists of a condensing coil, a pump, a cool water bath and a valve. The condensing coil is used to condense the vapor produced in the pool boiling and the condensed liquid returns to the glass chamber by gravity.

The heat flux through the test surface is controlled by adjusting the heating power of the cartridge heater. The saturation pressure is controlled by two methods: (1) adjusting the heating power of the electrical heating wire and (2) adjusting the mass flow rate of the cool water by controlling the opening of the valve in the condensation loop.

\subsection{Experimental procedure}

The nucleate pool boiling heat transfer characteristics of the refrigerant/oil mixture with nanoparticles is tested at the heat flux from 10 to $80 \mathrm{~kW} \mathrm{~m}^{-2}$, and the saturation pressure of $101.3 \mathrm{kPa}$. Before each experiment, the air in transparent glass chamber is removed by a vacuum pump firstly, and then the test fluid is charged into the transparent glass chamber and heated to the saturation pressure. The measurement starts from the lowest heat flux $\left(10 \mathrm{~kW} \mathrm{~m}^{-2}\right)$ at a fixed saturation pressure. If the temperature variation of copper block is smaller than $1{ }^{\circ} \mathrm{C}$ in $10 \mathrm{~min}$, the heat transfer process can be considered to reach a steady state. For example, in the experiment for R113/VG68/50 $\mathrm{nm}-\mathrm{Cu}\left(\omega_{\mathrm{n}}=20 \mathrm{wt} \%, x_{\mathrm{n}, \mathrm{o}}=1 \mathrm{wt} \%\right)$ at the heat flux of $50 \mathrm{~kW} \mathrm{~m}^{-2}$, it is observed that the variations of the measured five temperatures on the copper block are all smaller than $0.5^{\circ} \mathrm{C}$ in $10 \mathrm{~min}$ when the steady state is reached. After that, the liquid temperature, the five temperatures on the cooper block and the heating power to the copper block are recorded. Then the heat flux is increased by the increment of $5 \mathrm{~kW} \mathrm{~m}^{-2}$, and the above procedure is repeated. After each experiment, pure R113 is injected into the boiling chamber to remove the nanoparticles/oil suspension from the glass chamber and the test surface. The test surface is also cleaned by acetone to remove the sticking nanoparticles, ensuring no change of the test surface characteristics.

\subsection{Test conditions}

Test conditions are tabulated in Table 3. All signals of temperature, pressure are collected by a data acquisition system and transmitted to a computer after the system reaches a steady state. 


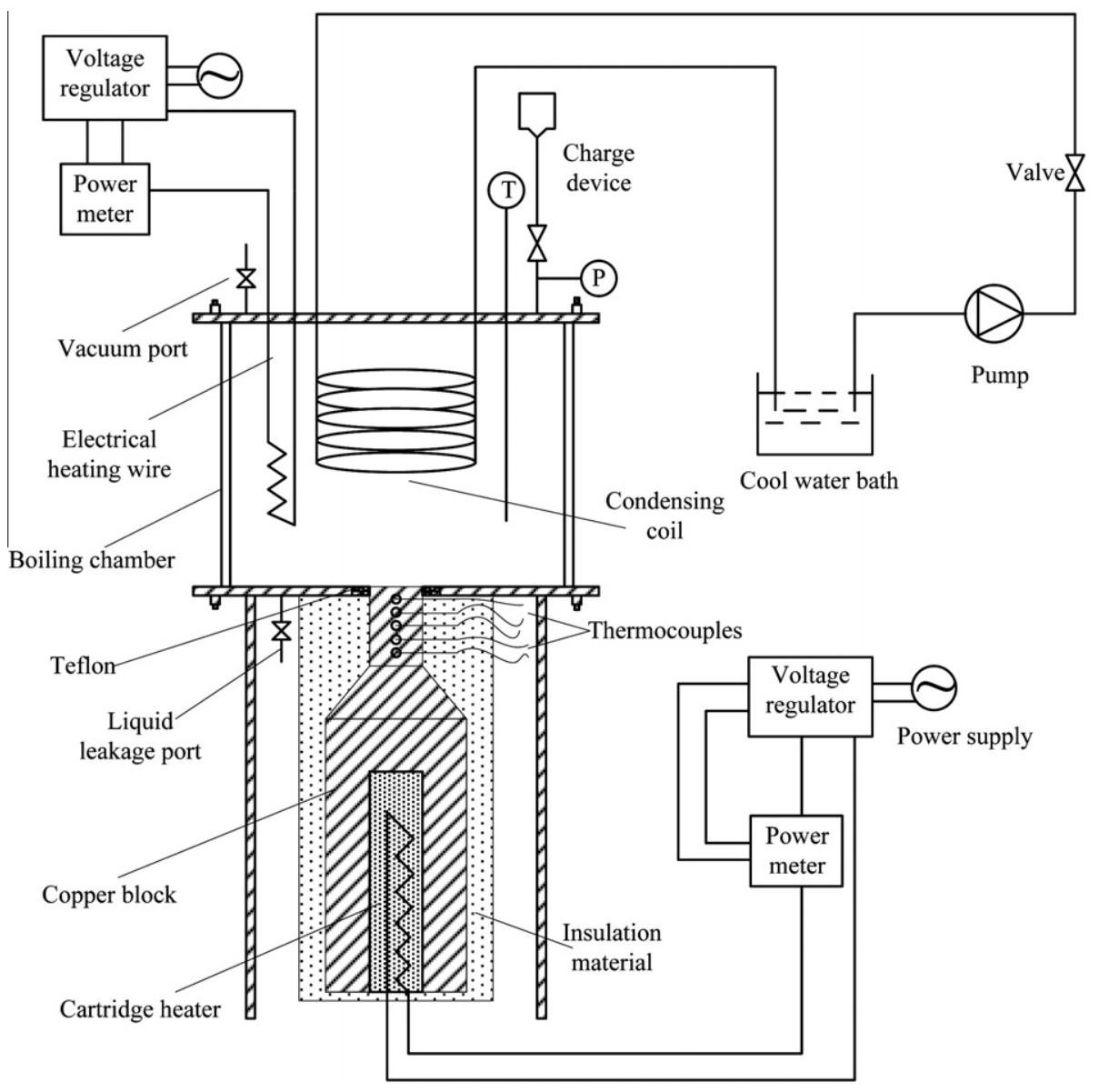

Fig. 2. Schematic diagram of experimental setup.

\section{Data reduction and uncertainties}

The nucleate pool boiling heat transfer coefficient, $h$, is calculated as:

$h=q /\left(T_{\mathrm{w}}-T_{\mathrm{sat}}\right)$

where $q$ is the heat flux, $T_{\mathrm{w}}$ is the test surface temperature, and $T_{\text {sat }}$ is the saturated liquid temperature.

The heat flux, $q$, is calculated by Eqs. (5) and (6) based on the one-dimensional heat conduction equation:

$q=-\left.\lambda_{\mathrm{c}} \frac{d T}{d z}\right|_{\mathrm{w}}$

$T=a_{1}+a_{2} z$

where $\lambda_{\mathrm{c}}$ is the copper thermal conductivity, $z$ is the coordinate perpendicular to the test surface, $a_{1}$ and $a_{2}$ are constants correlated based on the measured five temperatures on the copper block, i.e., $T_{1}, T_{2}, T_{3}, T_{4}$ and $T_{5}$ (the locations of $T_{1}, T_{2}, T_{3}, T_{4}$ and $T_{5}$ are shown in Fig. 3). The one-dimensional temperature distribution on the copper block is shown in Fig. 4. As an example, the test conditions showed in Fig. 4 cover the test fluid of R113/VG68/20 nm-Cu $\left(\omega_{\mathrm{n}}=20 \mathrm{wt} \%, x_{\mathrm{n}, \mathrm{o}}=1 \mathrm{wt} \%\right)$ and the heat fluxes of 10,50 and $80 \mathrm{~kW} \mathrm{~m}^{-2}$. It can be seen from Fig. 4 that the measured five temperatures are in the linear distribution.

The test surface temperature, $T_{\mathrm{w}}$, is calculated as:

$T_{\mathrm{w}}=\left.\left(a_{1}+a_{2} z\right)\right|_{z=0}=a_{1}$

The saturated liquid temperature, $T_{\text {sat }}$, changes with the variations of the compositions of refrigerant/oil mixture with nanoparticles. The value of the saturated liquid temperature is measured by the K-type thermocouple, and the measured value of the saturated liquid temperature can reflect its change with the variations of the compositions of refrigerant/oil mixture with nanoparticles.

The uncertainty of nucleate pool boiling heat transfer coefficient, $\Delta h$, is calculated as:

$\Delta h=\sqrt{\left(\frac{\partial h}{\partial q}\right)^{2} \Delta q^{2}+\left(\frac{\partial h}{\partial T_{\mathrm{w}}}\right)^{2} \Delta T_{\mathrm{w}}^{2}+\left(\frac{\partial h}{\partial T_{\mathrm{sat}}}\right)^{2} \Delta T_{\mathrm{sat}}^{2}}$

By substituting Eqs. (4)-(8), the relative uncertainty of nucleate pool boiling heat transfer coefficient is calculated as:

$\frac{\Delta h}{h}=\sqrt{\left(\frac{\Delta q}{q}\right)^{2}+\left(\frac{\Delta T_{\mathrm{w}}}{T_{\mathrm{w}}-T_{\mathrm{sat}}}\right)^{2}+\left(\frac{\Delta T_{\mathrm{sat}}}{T_{\mathrm{w}}-T_{\mathrm{sat}}}\right)^{2}}$

The maximum relative uncertainty of nucleate pool boiling heat transfer coefficient is obtained at the condition of the smallest test surface temperature and the largest saturated liquid temperature, and calculated to be $9.2 \%$.

\section{Experimental results and analysis}

\subsection{Effect of nanoparticle size on the nucleate pool boiling heat transfer coefficient of refrigerant/oil mixture with nanoparticles}

The nucleate pool boiling heat transfer coefficients of R113/oil mixtures with three different size $\mathrm{Cu}$ nanoparticles $\left(d_{\mathrm{p}}=20,50\right.$ and $80 \mathrm{~nm}$ ) are shown in Fig. 5. It can be seen from Fig. 5 that the R113/oil mixture with $\mathrm{Cu}$ nanoparticles has higher nucleate pool boiling heat transfer coefficient than the R113/oil mixture without nanoparticles, meaning the presence of nanoparticles 


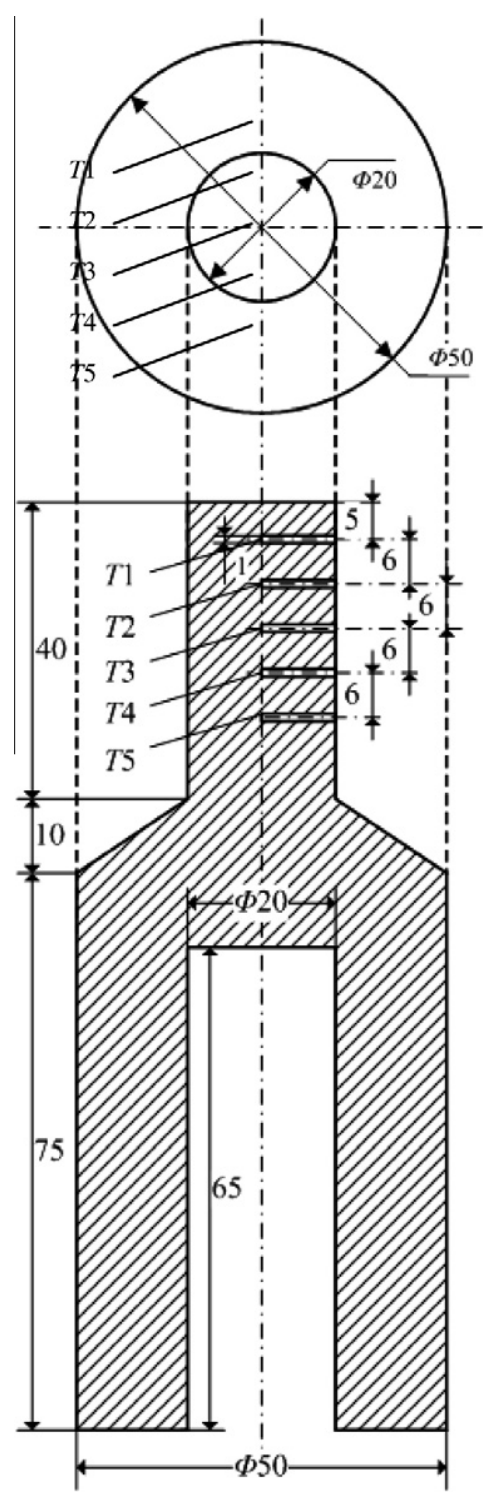

Fig. 3. The copper block test section (note: all dimensions are in $\mathrm{mm}$ ).

enhances the nucleate pool boiling heat transfer. The enhancement increases with the decrease of nanoparticle size, and it can reach up to $49 \%$ at the smallest nanoparticle size $\left(d_{\mathrm{p}}=20 \mathrm{~nm}\right)$ under the present experimental conditions. The possible reasons for the nucleate pool boiling heat transfer enhancement are as follows: (1) The nano-scale porous layer forms on the heating surface due to the interaction between the nanoparticles and the heating surface $[8,10,19]$, thus the active nucleation site density increases [20], which leads to the enhancement of the nucleate pool boiling heat transfer. (2) The nanoparticles in the lubricant excess layer interact with bubbles, inducing secondary nucleation on the bubbles [10], which leads to the enhancement of the nucleate pool boiling heat transfer. (3) The thermal conductivity of Cu nanoparticle $\left(398 \mathrm{~W} \mathrm{~m}^{-1} \mathrm{~K}^{-1}\right)$ is four or three orders of magnitude higher than that of $\mathrm{R} 113\left(0.064 \mathrm{~W} \mathrm{~m}^{-1} \mathrm{~K}^{-1}\right)$ or lubricating oil $\left(0.13 \mathrm{~W} \mathrm{~m}^{-1} \mathrm{~K}^{-1}\right)$, respectively, so the thermal conductivity of $\mathrm{R} 113$ /oil mixture with $\mathrm{Cu}$ nanoparticles is larger than that of R113/oil mixture. The increase of thermal conductivity causes the decrease of the superheat degree of the bubble nucleation, which leads to the enhancement of the nucleate pool boiling heat transfer.

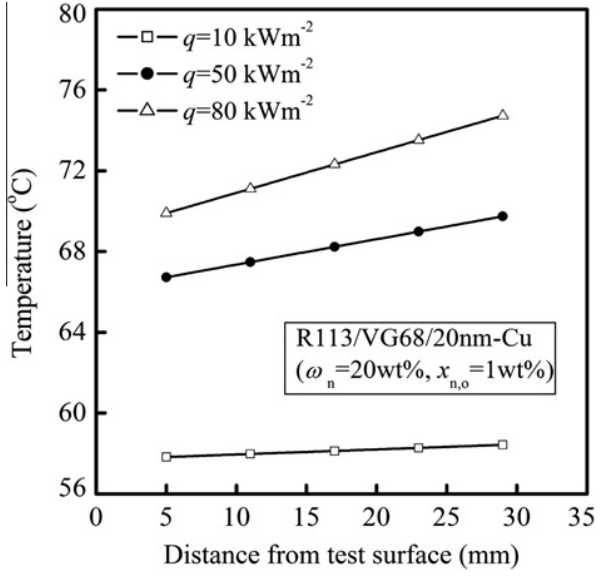

Fig. 4. One-dimensional temperature distribution on the copper block.

Fig. 5 also shows that the nucleate pool boiling heat transfer coefficient of R113/oil mixture with Cu nanoparticles increases by a maximum of $23.8 \%$ with the decrease of nanoparticle size from 80 to $20 \mathrm{~nm}$ under the present experimental conditions, which means the R113/oil mixture with smaller size Cu nanoparticles has higher nucleate pool boiling heat transfer coefficient at a fixed nanoparticle concentration in the nanoparticles/oil suspension $\left(\omega_{\mathrm{n}}\right)$ and nanoparticles/oil suspension concentration $\left(x_{n, 0}\right)$. The reasons for this phenomenon include the following two aspects.

(1) Effect of nanoparticle size on the thermophysical properties of refrigerant/oil mixture with nanoparticles.

Thermal conductivity and surface tension have influences on the bubble nucleation during the nucleate pool boiling process of fluid. Increasing thermal conductivity and decreasing surface tension will decrease the superheat degree of bubble nucleation, causing the enhancement of the nucleate pool boiling heat transfer. The surface tension of nanofluid is very close to that of the host fluid [17], so the effect of nanoparticle size on the surface tension of refrigerant/oil mixture with nanoparticles can be ignored. Meanwhile, the thermal conductivity of nanofluid increases with the decrease of nanoparticle size [1-3], thus the superheat degree of bubble nucleation for refrigerant/oil mixture with nanoparticles decreases with the decrease of nanoparticle size, which leads to the enhancement of nucleate pool boiling heat transfer coefficient with the decrease of nanoparticle size.

(2) Effect of nanoparticle size on the interaction between nanoparticles and heating surface.

The interaction between nanoparticles and heating surface is decided by the nanoparticle size $\left(d_{\mathrm{p}}\right)$ and the heating surface roughness $\left(R_{\mathrm{a}}\right)$. The number of nucleation sites is decreased when the average particle size is of the order of the surface roughness, and is greatly increased when the average particle size is much smaller than the surface roughness [13]. Therefore, when the ratio of heating surface roughness to nanoparticle size $\left(R_{\mathrm{a}} / d_{\mathrm{p}}\right)$ is much larger than 1 , the nucleate pool boiling heat transfer is enhanced; otherwise, the nucleate pool boiling heat transfer is deteriorated. In the present study, $R_{\mathrm{a}} / d_{\mathrm{p}}$ is from 20 to 80 , so the nucleate pool boiling heat transfer of refrigerant/oil mixture with nanoparticles is always enhanced. At a certain heating surface roughness, decreasing nanoparticle size can intensify the split of a single nucleation site into multiple ones as well as increase the interaction force between nanopaticles and heating surface [13], so the 


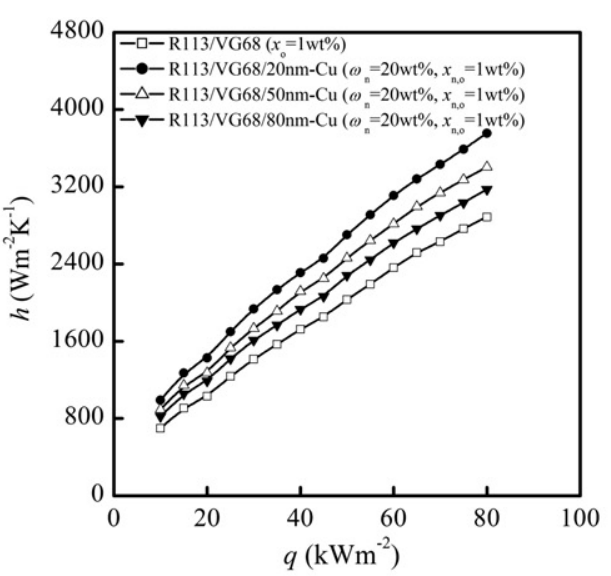

(a) $\omega_{\mathrm{n}}=20 \mathrm{wt} \%, x_{\mathrm{n}, \mathrm{o}}=1 \mathrm{wt} \%$

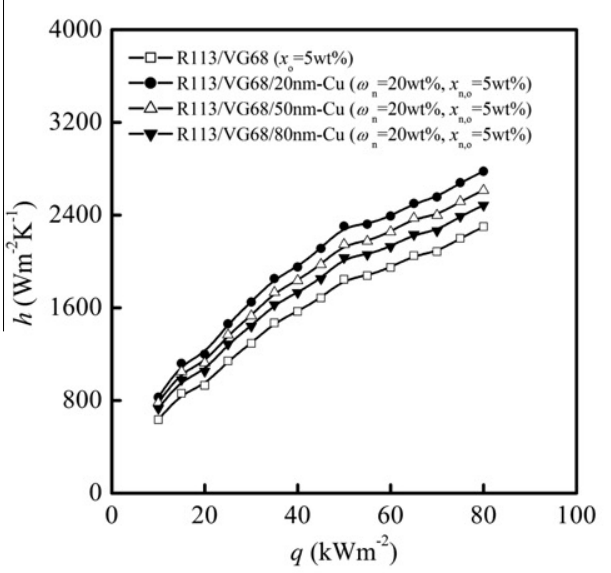

(c) $\omega_{\mathrm{n}}=20 \mathrm{wt} \%, x_{\mathrm{n}, \mathrm{o}}=5 \mathrm{wt} \%$

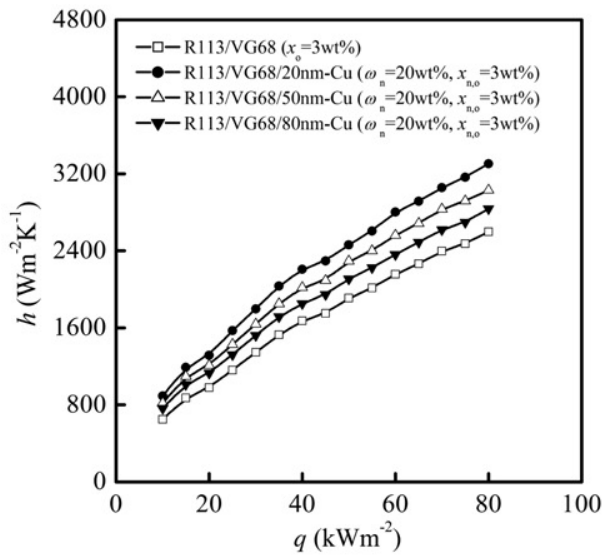

(b) $\omega_{\mathrm{n}}=20 \mathrm{wt} \%, x_{\mathrm{n}, \mathrm{o}}=3 \mathrm{wt} \%$

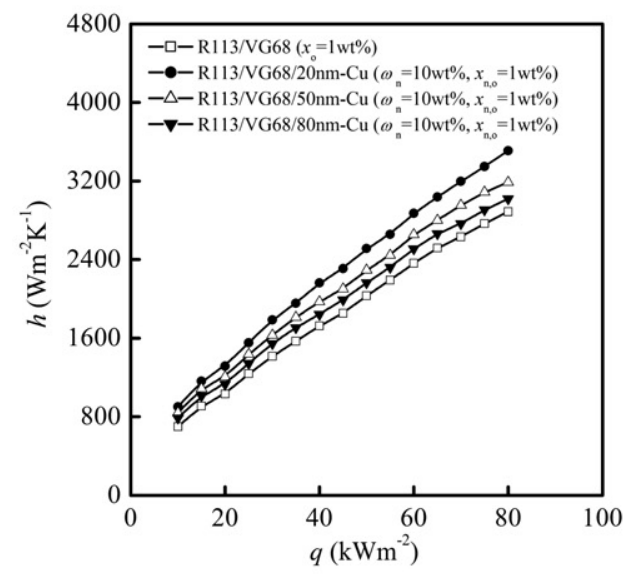

(d) $\omega_{\mathrm{n}}=10 \mathrm{wt} \%, x_{\mathrm{n}, \mathrm{o}}=1 \mathrm{wt} \%$

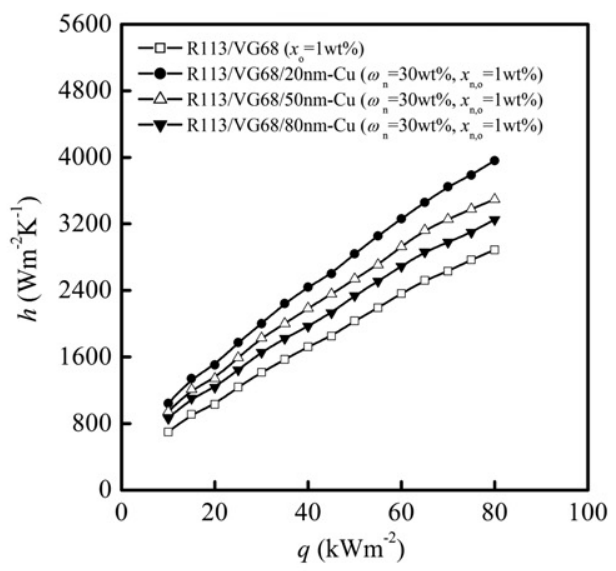

(e) $\omega_{\mathrm{n}}=30 \mathrm{wt} \%, x_{\mathrm{n}, \mathrm{o}}=1 \mathrm{wt} \%$

Fig. 5. Nucleate pool boiling heat transfer coefficients of R113/oil mixtures with three different size Cu nanoparticles $\left(d_{\mathrm{p}}=20 \mathrm{~nm}, 50 \mathrm{~nm}\right.$ and $\left.80 \mathrm{~nm}\right)$.

nucleate pool boiling heat transfer coefficient increases with the decrease of nanoparticle size.

\subsection{Nanoparticle size impact factor, $F_{S}$}

In order to analyze the effect of nanoparticle size on the nucleate pool boiling heat transfer quantitatively, nanoparticle size impact factor, $F_{\mathrm{s}}$, is defined as the ratio of the nucleate pool boiling heat transfer coefficient of refrigerant/oil mixture with nanoparticles to that of refrigerant/oil mixture, presented as Eq. (10):
$F_{\mathrm{s}}=h_{\mathrm{r}, \mathrm{n}, \mathrm{o}} / h_{\mathrm{r}, \mathrm{o}}$

where $h_{\mathrm{r}, \mathrm{n}, \mathrm{o}}$ is the nucleate pool boiling heat transfer coefficient of refrigerant/oil mixture with nanoparticles, and $h_{r, o}$ is the nucleate pool boiling heat transfer coefficient of refrigerant/oil mixture.

Fig. 6 shows the nanoparticle size impact factor $\left(F_{\mathrm{s}}\right)$ changing with the heat flux. From Fig. 6(a)-(c), it can be seen that at a fixed nanoparticle concentration in the nanoparticles/oil suspension $\left(\omega_{\mathrm{n}}=20 \mathrm{wt} \%\right), F_{\mathrm{s}}$ are in the ranges of $1.10-1.42,1.09-1.38$, and 1.08-1.31 when the values of nanoparticles/oil suspension concentration $\left(x_{\mathrm{n}, \mathrm{o}}\right)$ are 1,3 and $5 \mathrm{wt} \%$, respectively. $F_{\mathrm{s}}$ increases with the 
decrease of $x_{n, 0}$. The possible reason for this phenomenon is as follows. The viscosity of refrigerant/oil mixture with nanoparticles increases with the increase of $x_{n, 0}$. The increase of viscosity causes the decrease of Brownian motion velocities of nanoparticles as well as the collision possibility between nanoparticles and heating surface, and then weakens the effect of nanoparticle size on the interaction between nanoparticles and heating surface.

From Fig. 6(a), (d) and (e), it can be seen that at a fixed nanoparticles/oil suspension concentration $\left(x_{\mathrm{n}, \mathrm{o}}=1 \mathrm{wt} \%\right), F_{\mathrm{s}}$ are in the ranges of $1.05-1.29,1.10-1.42$, and $1.12-1.49$ when the values of nanoparticle concentration in the nanoparticles/oil suspension $\left(\omega_{\mathrm{n}}\right)$ are 10,20 and $30 \mathrm{wt} \%$, respectively. $F_{\mathrm{s}}$ increases with the increase of $\omega_{\mathrm{n}}$, and this phenomenon might be resulted from that the collision possibility between nanoparticles and heating surface increases with the increase of $\omega_{n}$, causing the effect of nanoparticle size on the interaction between nanoparticles and heating surface to be obvious.

\section{A general nucleate pool boiling heat transfer coefficient correlation for refrigerant/oil mixtures with nanoparticles}

\subsection{Basic idea for the development of the general correlation}

The nucleate pool boiling heat transfer characteristics of a fluid are affected by the fluid type and heating surface characteristics. For the refrigerant/oil mixtures with nanoparticles, the factors influencing the fluid type and the heating surface characteristics mainly include the nanoparticle type, the host fluid (i.e., refrigerant/oil mixture) type, and the nanoparticle size. Therefore, the above three factors should be reflected in the nucleate pool boiling heat transfer coefficient correlation for refrigerant/oil mixtures with nanoparticles.

Peng et al. correlation [11] is the only existing nucleate pool boiling heat transfer coefficient correlation for refrigerant/oil mixtures with nanoparticles, and is developed based on Rohsenow correlation [21]. In Peng et al. correlation, the thermophysical properties of refrigerant/oil mixture with nanoparticles are used instead of the properties of pure fluid in Rohsenow correlation, so the effects of nanoparticle type and host fluid type can be reflected. However, the effect of nanoparticle size can not be reflected in Peng et al. correlation for the following two reasons: (1) The coefficient depending on the experimental data, $C_{\mathrm{sf}}$, is the function of the nanoparticle concentration in the nanopartilces/ oil suspension $\left(\omega_{n}\right)$ and the nanopartilces/oil suspension concentration $\left(x_{n, 0}\right)$, and not related to the nanoparticle size. (2) $C_{\mathrm{sf}}$ is correlated based on the experimental data of the nucleate pool boiling heat transfer for refrigerant/oil mixture with nanoparticles of only

\subsection{Development and verification of the general correlation}

By using the thermophysical properties of refrigerant/oil mixtures with nanoparticles instead of the thermophysical properties of pure fluid in Rohsenow correlation, the nucleate pool boiling heat transfer coefficient of refrigerant/oil mixtures with different size nanoparticles, $h_{\mathrm{r}, \mathrm{n}, \mathrm{o}}$, can be calculated by Eqs. (11) and (12):

$h_{r, n, o}=q / \Delta T_{\mathrm{b}}$

$$
\Delta T_{\mathrm{b}}=\frac{C_{\mathrm{sf}} h_{\mathrm{fg}}}{C_{p, \mathrm{r}, \mathrm{n}, \mathrm{o}, \mathrm{f}}}\left[\frac{q}{\mu_{\mathrm{r}, \mathrm{n}, \mathrm{o}, \mathrm{f}} h_{\mathrm{fg}}} \sqrt{\frac{\sigma_{\mathrm{r}, \mathrm{n}, \mathrm{o}}}{g\left(\rho_{\mathrm{r}, \mathrm{n}, \mathrm{o}, \mathrm{f}}-\rho_{\mathrm{r}, \mathrm{g}}\right)}}\right]^{0.33}\left[\frac{C_{p, \mathrm{r}, \mathrm{n}, \mathrm{o}, \mathrm{f}} \mu_{\mathrm{r}, \mathrm{n}, \mathrm{o}, \mathrm{f}}}{\lambda_{\mathrm{r}, \mathrm{n}, \mathrm{o}, \mathrm{f}}}\right]^{n}
$$

where $q$ is the heat flux; $\Delta T_{\mathrm{b}}$ is the temperature difference; $C_{p, \mathrm{r}, \mathrm{n}, \mathrm{o}, \mathrm{f}}$, $\mu_{\mathrm{r}, \mathrm{n}, \mathrm{o}, \mathrm{f}}$ and $\lambda_{\mathrm{r}, \mathrm{n}, \mathrm{o}, \mathrm{f}}$ are the isobaric specific heat, the dynamic viscosity and the thermal conductivity of liquid refrigerant/oil mixture with nanoparticles, respectively; $\sigma_{\mathrm{r}, \mathrm{n}, \mathrm{o}}$ is the surface tension of refrigerant/oil mixture with nanoparticles, $\rho_{\mathrm{r}, \mathrm{g}}$ and $\rho_{\mathrm{r}, \mathrm{n}, \mathrm{o}, \mathrm{f}}$ are the densities of vapor refrigerant and liquid refrigerant/oil mixture with nanoparticles, respectively; $h_{\mathrm{fg}}$ is the latent heat of vaporization. The methods for calculating the properties of the nanopartilces/oil suspension, the refrigerant/oil mixture with nanoparticles, and the refrigerant/oil mixture are presented in Appendices A-C, respectively.

In Eq. (12), the coefficient depending on the experimental data, $C_{\mathrm{sf}}$, is expressed as Eq. (13):

$C_{\mathrm{sf}}=a+b \frac{d_{\mathrm{p}}}{d_{0}}+c \omega_{\mathrm{n}}+d x_{\mathrm{n}, \mathrm{o}}$

where $d_{0}$ is the benchmark nanoparticle size, and the value of $d_{0}$ is $100 \mathrm{~nm}$. The five coefficients of $n, a, b, c$ and $d$ in Eqs. (12) and (13) should be fitted according to the experimental data of the refrigerant/oil mixtures with different size nanoparticles. In the present study, total 818 data are used for the fitting, including 225 experimental data of R113/oil mixtures with three different size Cu nanoparticles (i.e., 20, 50 and $80 \mathrm{~nm}$ ) in the present study, 458 experimental data of R134a/oil mixture with $30 \mathrm{~nm} \mathrm{CuO} \mathrm{nanoparti-}$ cles presented by Kedzierski and Gong [10], 135 experimental data of R113/oil mixture with $10 \mathrm{~nm}$ diamond nanoparticles presented by Peng et al. [11]. Experimental conditions of the total 818 data cover the nanoparticle size from 10 to $80 \mathrm{~nm}$, the nanoparticle concentrations in the nanolubricant from 0 to $30 \mathrm{wt} \%$, and the nanolubricant concentrations from 0 to $5 \mathrm{wt} \%$.

By nonlinear programming solution method, the five coefficients of $n, a, b, c$ and $d$ can be obtained as 1.3068, 0.0093, $0.00356,-0.0048$ and 0.0025 , respectively. Therefore, the general correlation can be expressed as Eq. (14):

$h_{\mathrm{r}, \mathrm{n}, \mathrm{o}}=\frac{q}{\frac{h_{\mathrm{fg}}}{C_{p, r, \mathrm{n}, \mathrm{o}, \mathrm{f}}}\left(0.0093+0.00356 \frac{d_{\mathrm{p}}}{d_{0}}-0.0048 \omega_{\mathrm{n}}+0.0025 x_{\mathrm{n}, \mathrm{o}}\right)\left[\frac{q}{\mu_{\mathrm{r}, \mathrm{n}, \mathrm{f}, \mathrm{f}} h_{\mathrm{fg}}} \sqrt{\frac{\sigma_{\mathrm{r}, \mathrm{n}, \mathrm{o}}}{g\left(\rho_{\mathrm{r}, \mathrm{n}, \mathrm{f}, \mathrm{f}}-\rho_{\mathrm{r}, \mathrm{g}}\right)}}\right]^{0.33}\left[\frac{c_{p, r, \mathrm{n}, \mathrm{f}} \mu_{\mathrm{r}, \mathrm{n}, \mathrm{f}, \mathrm{f}}}{k_{\mathrm{r}, \mathrm{n}, \mathrm{f}, \mathrm{f}}}\right]^{1.3068}}$

one size. Therefore, a general correlation should be developed, reflecting not only the effects of nanoparticle type and host fluid type but also the effect of nanoparticle size.

To reflect the effect of nanoparticle size, the following modifications should be made to Peng et al. correlation. (1) The coefficient depending on the experimental data, $C_{\mathrm{sf}}$, should be expressed as the function of nanoparticle size $\left(d_{p}\right)$, the nanoparticle concentration in the nanopartilces/oil suspension $\left(\omega_{\mathrm{n}}\right)$ and the nanopartilces/oil suspension concentration $\left(x_{\mathrm{n}, \mathrm{o}}\right)$, shown as $C_{\mathrm{sf}}=f\left(d_{\mathrm{p}}, \omega_{\mathrm{n}}, x_{\mathrm{n}, \mathrm{o}}\right)$. (2) $C_{\mathrm{sf}}$ should be correlated based on the experimental data of the nucleate pool boiling heat transfer for refrigerant/oil mixture with different size nanoparticles.
The general correlation is verified with the experimental data, as shown in Fig. 7. It can be seen from Fig. 7(a)-(c) that the predicted values of the general correlation can agree with $97 \%$ of the experimental data of R113/oil mixtures with three different size Cu nanoparticles (i.e., 20, 50 and $80 \mathrm{~nm}$ ) in the present study within a deviation of $\pm 10 \%$. Fig. 7 (d) shows that the predicted values can agree with $88 \%$ of the experimental data of R134a/oil mixture with $30 \mathrm{~nm}$ $\mathrm{CuO}$ nanoparticles presented by Kedzierski and Gong [10] within a deviation of $\pm 20 \%$. Fig. 7 (e) shows that the predicted values can agree with $98 \%$ of the experimental data of R113/oil mixture with $10 \mathrm{~nm}$ diamond nanoparticles presented by Peng et al. [11] within a deviation of $\pm 15 \%$. In summary, the general correlation agrees with $93 \%$ of 


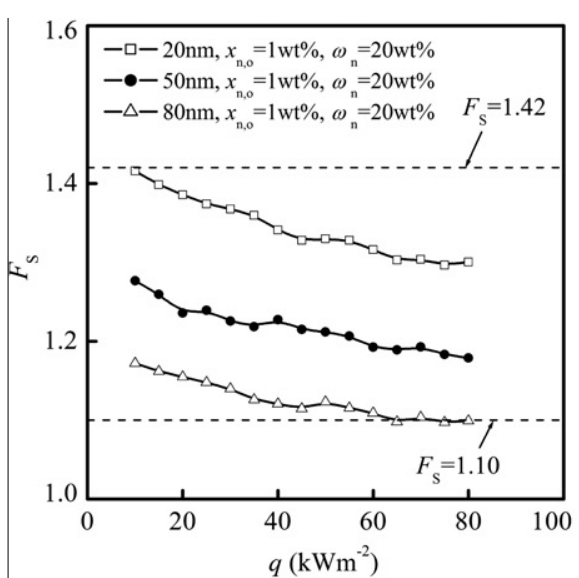

(a) $\omega_{\mathrm{n}}=20 \mathrm{wt} \%, x_{\mathrm{n}, \mathrm{o}}=1 \mathrm{wt} \%$

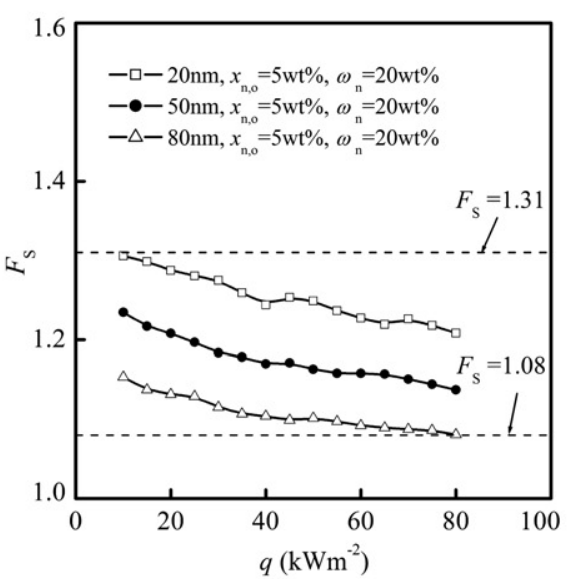

(c) $\omega_{\mathrm{n}}=20 \mathrm{wt} \%, x_{\mathrm{n}, \mathrm{o}}=5 \mathrm{wt} \%$

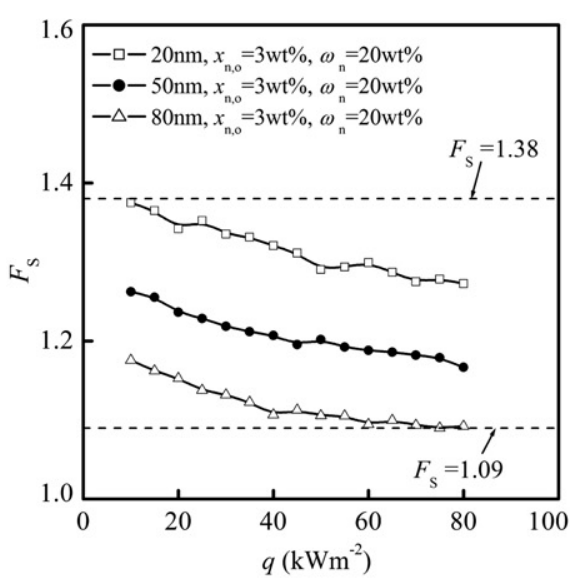

(b) $\omega_{\mathrm{n}}=20 \mathrm{wt} \%, x_{\mathrm{n}, \mathrm{o}}=3 \mathrm{wt} \%$

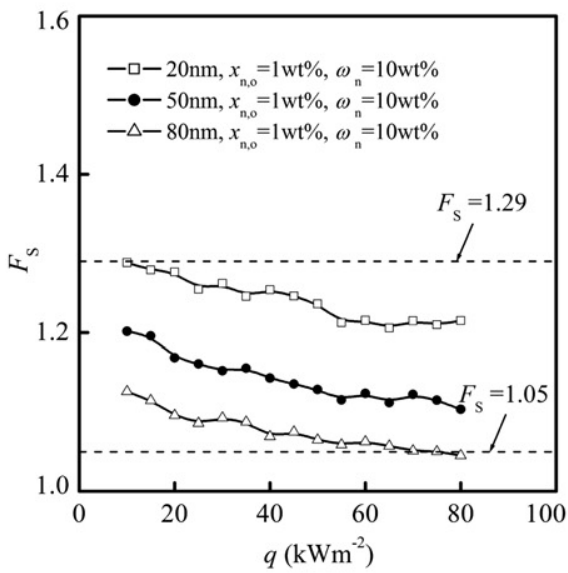

(d) $\omega_{\mathrm{n}}=10 \mathrm{wt} \%, x_{\mathrm{n}, \mathrm{o}}=1 \mathrm{wt} \%$

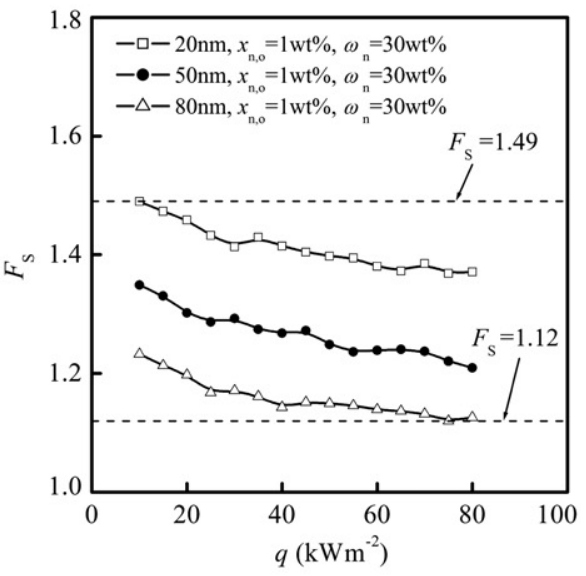

(e) $\omega_{\mathrm{n}}=30 \mathrm{wt} \%, x_{\mathrm{n}, \mathrm{o}}=1 \mathrm{wt} \%$

Fig. 6. Nanoparticle size impact factor $\left(F_{\mathrm{s}}\right)$ vs. heat flux.

the existing experimental data of refrigerant/oil mixture with nanoparticles within a deviation of $\pm 20 \%$.

\section{Conclusions}

Effect of nanoparticle size on nucleate pool boiling heat transfer characteristics of R113/oil mixture with $\mathrm{Cu}$ nanoparticles was investigated experimentally, and the following conclusions are obtained.
(1) The nucleate pool boiling heat transfer coefficient of R113/oil mixture with $\mathrm{Cu}$ nanoparticles increases by a maximum of $23.8 \%$ with the decrease of nanoparticle size from 80 to $20 \mathrm{~nm}$ under the present experimental conditions, meaning that the R113/oil mixture with smaller size $\mathrm{Cu}$ nanoparticles provides higher nucleate pool boiling heat transfer coefficient.

(2) The nanoparticle size impact factor $\left(F_{s}\right)$ increases with the decrease of nanoparticles/oil suspension concentration $\left(x_{n, 0}\right)$, and increases with the increase of nanoparticle 


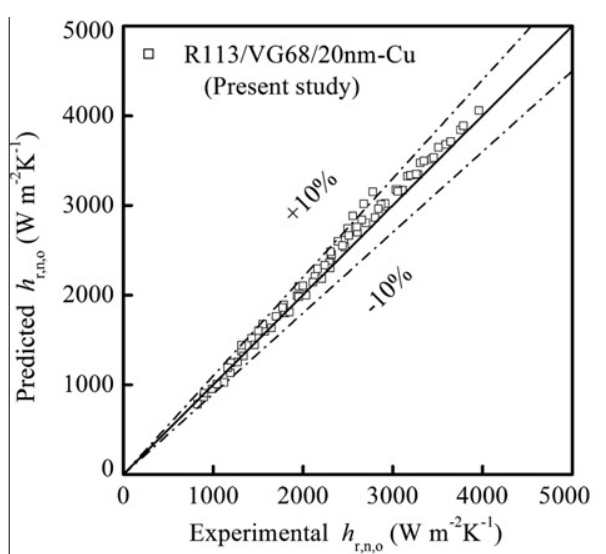

(a) R113/VG68/20nm-Cu

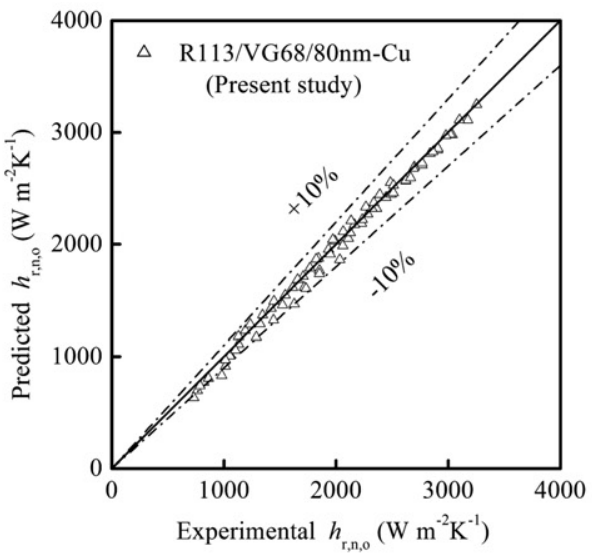

(c) R113/VG68/80nm-Cu

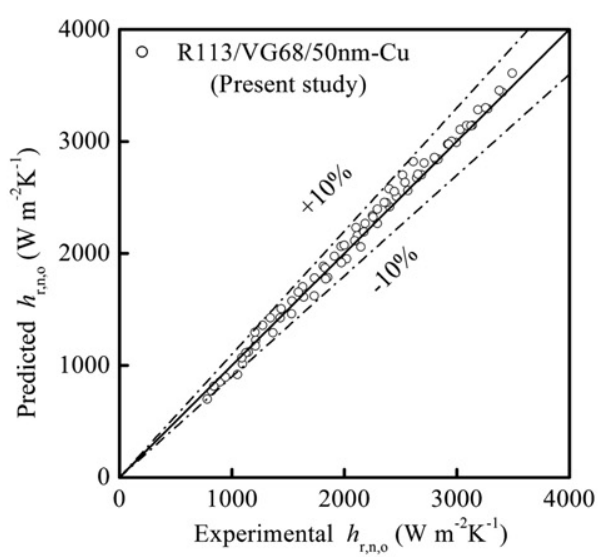

(b) R113/VG68/50nm-Cu

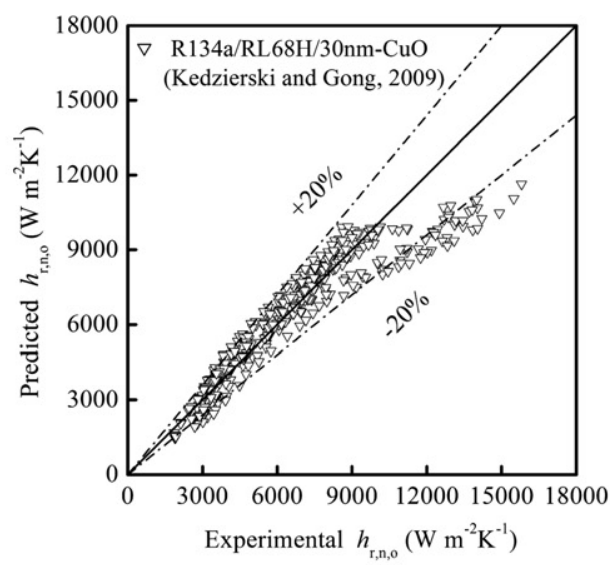

(d) R134a/RL68H/30nm-CuO

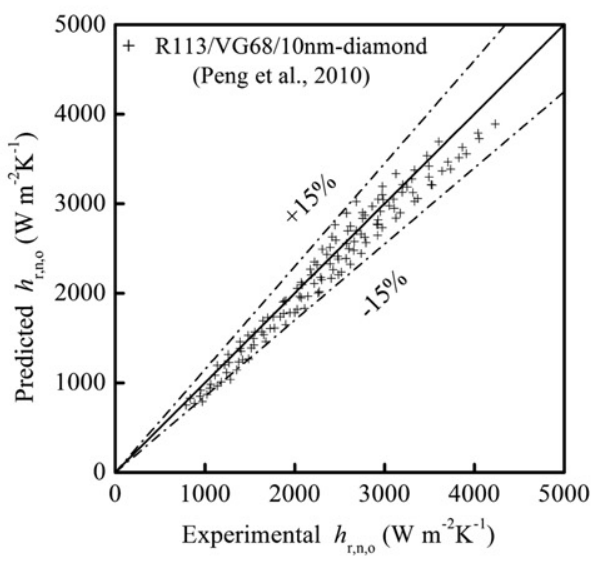

(e) R113/VG68/10nm-diamond

Fig. 7. Comparison of the predicted values of the general correlation with the experimental data.

concentration in the nanoparticles/oil suspension $\left(\omega_{\mathrm{n}}\right)$. At a fixed $\omega_{\mathrm{n}}$, the values of $F_{\mathrm{s}}$ are in the ranges of 1.10-1.42, $1.09-1.38$, and 1.08-1.31 when the values of $x_{\mathrm{n}, \mathrm{o}}$ are 1,3 and $5 \mathrm{wt} \%$, respectively; while at a fixed $x_{\mathrm{n}, \mathrm{o}}$, the values of $F_{\mathrm{s}}$ are in the ranges of $1.05-1.29,1.10-1.42$, and $1.12-1.49$ when the values of $\omega_{\mathrm{n}}$ are 10, 20 and $30 \mathrm{wt} \%$, respectively.

(3) A general nucleate pool boiling heat transfer coefficient correlation for refrigerant/oil mixtures with nanoparticles is proposed, reflecting not only the effects of nanoparticle type and host fluid type but also the effect of nanoparticle size. The predicted values of the general correlation agree with $93 \%$ of the existing experimental data of refrigerant/oil mixture with nanoparticles within a deviation of $\pm 20 \%$.

\section{Acknowledgements}

The authors gratefully acknowledge the support from the National Natural Science Foundation of China (Grant No. 50976065) and Shanghai Postdoctoral Scientific Program (Grant No. 09R21413500). 


\section{Appendix A. Calculation methods for the properties of nanoparticles/oil suspension}

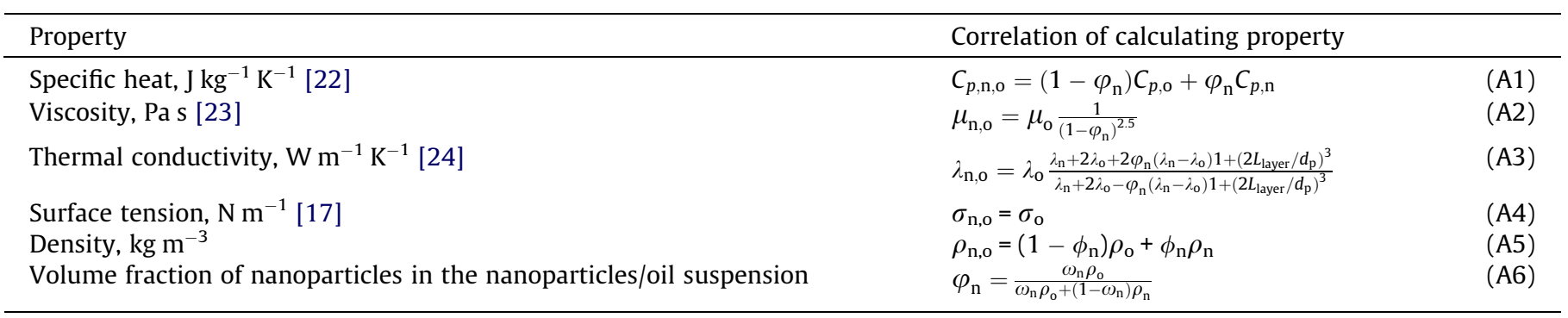

\section{Appendix B. Calculation methods for the properties of refrigerant/oil mixture with nanoparticles}

\begin{tabular}{lll}
\hline Property & Correlation of calculating property & \\
\hline Specific heat, J kg ${ }^{-1} \mathrm{~K}^{-1}[25]$ & $C_{p, \mathrm{r}, \mathrm{n}, \mathrm{o}, \mathrm{f}}=\left(1-x_{\mathrm{n}, \mathrm{o}}\right) C_{p, \mathrm{r}, \mathrm{f}}+x_{\mathrm{n}, \mathrm{o}} C_{p, n, \mathrm{o}}$ & $(\mathrm{A} 7)$ \\
Viscosity, Pa s [26] & $\mu_{\mathrm{r}, \mathrm{n}, \mathrm{o}, \mathrm{f}}=\mathrm{e}^{\left(x_{\mathrm{n}, \mathrm{o}} \ln \mu_{\mathrm{n}, \mathrm{o}}+\left(1-x_{\mathrm{n}, \mathrm{o}}\right) \ln \mu_{\mathrm{r}, \mathrm{f}}\right)}$ & $(\mathrm{A} 8)$ \\
Thermal conductivity, $\mathrm{W} \mathrm{m}^{-1} \mathrm{~K}^{-1}[27]$ & $\lambda_{\mathrm{r}, \mathrm{n}, \mathrm{f}}=\lambda_{\mathrm{r}, \mathrm{f}}\left(1-x_{\mathrm{n}, \mathrm{o}}\right)+\lambda_{\mathrm{n}, \mathrm{o}} x_{\mathrm{n}, \mathrm{o}}-0.72 x_{\mathrm{n}, \mathrm{o}}\left(1-x_{\mathrm{n}, \mathrm{o}}\right)\left(\lambda_{\mathrm{n}, \mathrm{o}}-\lambda_{\mathrm{r}, \mathrm{f}}\right)$ & $(\mathrm{A} 9)$ \\
Surface tension, $\mathrm{N} \mathrm{m}^{-1}[25]$ & $\sigma_{\mathrm{r}, \mathrm{n}, \mathrm{o}}=\sigma_{\mathrm{r}}+\left(\sigma_{\mathrm{n}, \mathrm{o}}-\sigma_{\mathrm{r}}\right) x_{\mathrm{n}, \mathrm{o}}^{0.5}$ & $(\mathrm{~A} 10)$ \\
Density, $\mathrm{kg} \mathrm{m}^{-3}$ & $\rho_{\mathrm{r}, \mathrm{n}, \mathrm{o}, \mathrm{f}}=\left(\frac{x_{\mathrm{n}, \mathrm{o}}}{\rho_{\mathrm{n}, \mathrm{o}}}+\frac{1-x_{\mathrm{n}, \mathrm{o}}}{\rho_{\mathrm{r}, \mathrm{f}}}\right)^{-1}$ & $(\mathrm{~A} 11)$ \\
\hline
\end{tabular}

\section{Appendix C. Calculation methods for the properties of refrigerant/oil mixture}

\begin{tabular}{lll}
\hline Property & Correlation of calculating property & \\
\hline Specific heat, $\mathrm{J} \mathrm{kg}^{-1} \mathrm{~K}^{-1}[25]$ & $C_{p, \mathrm{r}, \mathrm{o}, \mathrm{f}}=\left(1-x_{\mathrm{o}}\right) C_{p, \mathrm{r}, \mathrm{f}}+x_{\mathrm{o}} C_{p, \mathrm{o}}$ & $(\mathrm{A} 12)$ \\
Viscosity, Pa s [26] & $\mu_{\mathrm{r}, \mathrm{o}, \mathrm{f}}=\mathrm{e}^{\left(x_{0} \ln \mu_{\mathrm{o}}+\left(1-x_{0}\right) \ln \mu_{\mathrm{r}, \mathrm{f}}\right)}$ & $(\mathrm{A} 13)$ \\
Thermal conductivity, $\mathrm{W} \mathrm{m}^{-1} \mathrm{~K}^{-1}[27]$ & $\lambda_{\mathrm{r}, \mathrm{f}, \mathrm{f}}=\lambda_{\mathrm{r}, \mathrm{f}}\left(1-x_{\mathrm{o}}\right)+\lambda_{\mathrm{o}} x_{\mathrm{o}}-0.72 x_{\mathrm{o}}\left(1-x_{\mathrm{o}}\right)\left(\lambda_{\mathrm{o}}-\lambda_{\mathrm{r}, \mathrm{f}}\right)$ & $(\mathrm{A} 14)$ \\
Surface tension, $\mathrm{N} \mathrm{m}^{-1}[25]$ & $\sigma_{\mathrm{r}, \mathrm{o}}=\sigma_{\mathrm{r}}+\left(\sigma_{\mathrm{o}}-\sigma_{\mathrm{r}}\right) x_{\mathrm{o}}^{0.5}$ & $(\mathrm{~A} 15)$ \\
Density, $\mathrm{kg} \mathrm{m}^{-3}$ & $\rho_{\mathrm{r}, \mathrm{o}, \mathrm{f}}=\left(\frac{x_{0}}{\rho_{\mathrm{o}}}+\frac{1-x_{\mathrm{o}}}{\rho_{\mathrm{r}, \mathrm{f}}}\right)^{-1}$ & $(\mathrm{~A} 16)$ \\
\hline
\end{tabular}

\section{References}

[1] H.Q Xie, M. Fujii, X. Zhang, Effect of interfacial nanolayer on the effective thermal conductivity of nanoparticle-fluid mixture, Int. J. Heat Mass Transfer 48 (14) (2005) 2926-2932.

[2] W.Q. Lu, Q.M. Fan, Study for the particle's scale effect on some thermophysica properties of nanofluids by a simplified molecular dynamics method, Eng. Anal. Boundary Elem. 32 (2008) 282-289.

[3] S.M.S. Murshed, K.C. Leong, C. Yang, Investigations of thermal conductivity and viscosity of nanofluids, Int. J. Therm. Sci. 47 (2008) 560-568.

[4] C.T. Nguyen, G. Roy, C. Gauthier, N. Galanis, Heat transfer enhancement using $\mathrm{Al}_{2} \mathrm{O}_{3}$-water nanofluid for an electronic liquid cooling system, Appl. Therm. Eng. 27 (2007) 1501-1506.

[5] S. Mirmasoumi, A. Behzadmehr, Effect of nanoparticles mean diameter on mixed convection heat transfer of a nanofluid in a horizontal tube, Int. J. Heat Fluid Flow 29 (2008) 557-566.

[6] K.B. Anoop, T. Sundararajan, S.K. Das, Effect of particle size on the convective heat transfer in nanofluid in the developing region, Int. J. Heat Mass Transfer 52 (2009) 2189-2195

[7] R.X. Wang, B. Hao, G.Z. Xie, A refrigerating system using HFC134a and mineral lubricant appended with $n-\mathrm{TiO}_{2}(\mathrm{R})$ as working fluids, Proceedings of the 4th International Symposium on HAVC, Tsinghua University Press, Beijing, China, 2003, pp. 888-892.

[8] K.J. Wang, K. Shiromoto, T. Mizogami, Experiment study on the effect of nanoscale particle on the condensation process, in: Proceeding of the 22nd International Congress of Refrigeration, Beijing, China, 2007, Paper No. B11005.

[9] S.S. Bi, L. Shi, L.L. Zhang, Application of nanoparticles in domestic refrigerators, Appl. Therm. Eng. 28 (2008) 1834-1843.

[10] M.A. Kedzierski, M. Gong, Effect of CuO nanolubricant on R134a pool boiling heat transfer, Int. J. Refrig. 32 (5) (2009) 791-799.

[11] H. Peng, G.L. Ding, H.T. Hu, W.T. Jiang, D.W. Zhuang, K.J. Wang, Nucleate pool boiling heat transfer characteristics of refrigerant/oil mixture with diamond nanoparticles, Int. J. Refrig. 33 (2) (2010) 347-358.
[12] V. Trisaksri, S. Wongwises, Nucleate pool boiling heat transfer of $\mathrm{TiO}_{2}-\mathrm{R} 141 \mathrm{~b}$ nanofluids, Int. J. Heat Mass Transfer 52 (5-6) (2009) 1582-1588.

[13] G. Prakash Narayan, K.B. Anoop, S.K. Das, Effect of surface particle interaction on boiling heat transfer of nanoparticle suspensions, J. Appl. Phys. 102 (2007) 074317.

[14] G. Prakash Narayan, K.B. Anoop, G. Sateesh, S.K. Das, Effect of surface orientation on pool boiling heat transfer of nanoparticle suspensions, Int. J. Multiphase Flow 34 (2008) 145-160.

[15] G.L. Ding, H. Peng, W.T. Jiang, Y.F. Gao, The migration characteristics of nanoparticles in the pool boiling process of nanorefrigerant and nanorefrigerant-oil mixture, Int. J. Refrig. 32 (1) (2009) 114-123.

[16] Z.H. Liu, L. Liao, Sorption and agglutination phenomenon of nanofluids on a plain heating surface during pool boiling, Int. J. Heat Mass Transfer 51 (2008) 2593-2602.

[17] S.K. Das, N. Putra, W. Roetzel, Pool boiling characteristics of nano-fluids, Int. J. Heat Mass Transfer 46 (5) (2003) 851-862.

[18] Z.H. Liu, J.G. Xiong, R. Bao, Boiling heat transfer characteristics of nanofluids in a flat heat pipe evaporator with micro-grooved heating surface, Int. J. Multiphase Flow 33 (2007) 1284-1295.

[19] K.J. Wang, G.L. Ding, W.T. Jiang, Development of nanorefrigerant and its rudiment property, in: Proceedings of the 8th International Symposium on Fluid Control, Measurement and Visualization, China Aerodynamics Research Society, Chengdu, China, 2005, Paper No. 13-13, pp. 1-6.

[20] S. Vemuri, K.J. Kim, Pool boiling of saturated FC-72 on nano-porous surface, Int. Commun. Heat Mass Transfer 32 (2005) 27-31.

[21] W.M. Rohsenow, A method of correlating heat transfer data for surface boiling of liquids, Trans. ASME 74 (1952) 969-976.

[22] B.C. Pak, Y.I. Cho, Hydrodynamic and heat transfer study of dispersed fluids with submicron metallic oxide particles, Exp. Heat Transfer 11 (2)(1998) 151170.

[23] H.C. Brinkman, The viscosity of concentrated suspensions and solution, J. Chem. Phys. 20 (1952) 571-581.

[24] W. Yu, S.U.S. Choi, The role of interfacial layers in the enhanced thermal conductivity of nanofluids: a renovated Maxwell model, J. Nanopart. Res. 5 (2003) 167-171. 
[25] M.K. Jensen, D.L. Jackman, Prediction of nucleate pool boiling heat transfer coefficients of refrigerant-oil mixtures, J. Heat Transfer 106 (1984) 184-190.

[26] M.A. Kedzierski, M.P. Kaul, Horizontal nucleate flow boiling heat transfer coefficient measurements and visual observations for R12, R134a, and R134a/ ester lubricant mixtures, in: Proceedings of the 6th International Symposium on Transport Phenomena in Thermal Engineering, Seoul, Korea, 1993, pp. 111116.

[27] J.J. Baustian, M.B. Pate, A.E. Bergles, Measuring the concentration of a flowing oil-refrigerant mixture: instrument test facility and initial results, ASHRAE Trans. 94 (1) (1988) 167-177. 